\title{
Feeding Students During COVID-19-Related School Closures: A Nationwide Assessment of Initial Responses
}

Gabriella M. McLoughlin, $\mathrm{PhD}^{1,2}$; Sheila Fleischhacker, $\mathrm{PhD}$, JD, $\mathrm{RD}^{3}$; Amelie A. Hecht, $\mathrm{PhD}^{4}$; Jared McGuirt, $\mathrm{PhD}, \mathrm{RD}^{5}$; Carolyn Vega, $\mathrm{MPH}^{6}$; Margaret Read, $\mathrm{MA}^{6}$; Uriyoán Colón-Ramos, $\mathrm{ScD}^{7}$; Caroline G. Dunn, $\mathrm{PhD}^{8}$

\begin{abstract}
Objective: To conduct a nationwide assessment of child nutrition administrative agencies' responses to meal service provision during coronavirus disease 2019-related school closures.

Design: Systematic coding of government websites (February-May 2020) regarding school meal provision in all 50 US states and the District of Columbia, 5 US territories, and the US Department of Interior Bureau of Indian Education.

Participants: All US jurisdictions $(\mathrm{N}=57)$.

Variables Measured: Seven coding criteria were established to assess the strengths and weaknesses of jurisdictions' responses derived from emergency declarations, school closure announcements, and government websites on emergency school meals.

Analysis: Descriptive analyses.

Results: Most jurisdictions mentioned school meal provisions in school closure announcements $(76.4 \%)$, provided easily interpretable information and/or maps about meal sites (57.9\%), and included detailed information about school meal provisions in their coronavirus disease 2019 landing webpages $(\mathrm{n}=26$, 51\%). Fewer provided updated and comprehensive implementation guidance (39.3\%), referenced school closures in emergency declarations (37.5\%), had clear communication/outreach to families $(21.4 \%)$, or partnered with antihunger organizations (11.6\%).

Conclusions and Implications: Understanding initial jurisdictions' approaches are critical to current and future emergency planning during school closures and reopening to help address food insecurity better, limit disease transmission, and prevent health disparities, particularly among at-risk populations.

Key Words: food insecurity, federal nutrition assistance, schools, COVID-19, policymaking (J Nutr Educ Behav. 2020; 52:1120-1130.)
\end{abstract}

Accepted September 28, 2020.

\footnotetext{
${ }^{1}$ Implementation Science Center for Cancer Control and Prevention Research Center, Brown School at Washington University in St. Louis, Washington University in St. Louis, St. Louis, $\mathrm{MO}$

${ }^{2}$ Division of Public Health Sciences, Department of Surgery, Washington University School of Medicine, Washington University in St. Louis, St. Louis, MO

${ }^{3}$ Georgetown University Law Center, Georgetown University, Washington, DC

${ }^{4}$ Department of Health Policy and Management, Johns Hopkins Bloomberg School of Public Health, Johns Hopkins University, Baltimore, MD

${ }^{5}$ Department of Nutrition, University of North Carolina-Greensboro, Greensboro, NC

${ }^{6}$ Share Our Strength, Washington, DC

${ }^{7}$ Department of Global Health, Milken Institute School of Public Health, George Washington University, Washington, DC

${ }^{8}$ Department of Health Policy and Management, Harvard T.H. Chan School of Public Health, Harvard University, Boston, MA

Conflict of Interest Disclosure: The authors have not stated any conflicts of interest.

Address for correspondence: Gabriella M. McLoughlin, PhD, Implementation Science Center for Cancer Control and Prevention Research Center, Brown School at Washington University in St. Louis, Washington University in St. Louis, One Brookings Dr, St. Louis, MO 63130; E-mail: gmcloughlin@wustl.edu

(C) 2020 Society for Nutrition Education and Behavior. Published by Elsevier Inc. All rights reserved.
}

https://doi.org/10.1016/j.jneb.2020.09.018

\section{INTRODUCTION}

The coronavirus disease 2019 (COVID-19) pandemic forced widespread school closures beginning mid-March 2020, affecting at least 124,000 US public and private schools serving at least 55.1 million students. ${ }^{1}$ The pandemic has created unexpected challenges for the administration of the US Department of Agriculture (USDA) school-based nutrition programs, threatening access to meals for the nearly 30 million children who participate in the National School Lunch Program (NSLP) and nearly 15 million children who participate in the School Breakfast Program (SBP) daily. ${ }^{2}$ The administering agencies for USDA school-based nutrition programs vary by state, US territory, or tribal nation (Public Law [PL] 93-638; PL 100-297). ${ }^{3-6}$ Each 
administrative agency works directly with local educational authorities (local education authorities [LEAs]; ie, school districts or schools) to sponsor the NSLP and SBP, among others. During the COVID-19 pandemic, part of these agencies' responsibilities included providing guidance on program implementation and outreach.

In response to the pandemic and resulting school closures, on March 18, 2020, Congress (PL 116-127) provided administrative flexibilities for USDA school-based nutrition programs and appropriations for expanded emergency nutrition assistance to eligible families impacted by school closures, known as Pandemic Electronic Benefits Transfer. ${ }^{7}$ Administrative agencies could seek waivers to (1) provide meals during pandemic-related school closures, even if increasing costs to the federal government; (2) approve noncongregate feeding sites outside the school/care setting; (3) adjust meal nutritional content if needed because of COVID19-related supply chain disruptions; and (4) modify administrative requirements that cannot be met because of COVID-19; among others. $^{8-11}$

This study aimed to conduct a novel nationwide assessment of child nutrition administrative agencies' responses and communications to internal (those involved in program operations; eg, LEAs) and external (those served or affected by the program; eg, participating families) stakeholders regarding meal service provision during the COVID-19 pandemic-related school closures. This information is crucial to strengthen the current and future emergency planning during school closures: schools in states with stronger nutrition standard policies are more likely to promote meal participation among families. ${ }^{12,13}$ In addition, providing clear and concise information to stakeholders regarding meal site locations, among other program information, is critical in promoting school meal participation. ${ }^{14}$ This is particularly important when targeting populations with low-income and that identify as racial/ethnic minorities, whose meal participation might be negatively impacted by lack of transportation or child care; public safety concerns including COVID-19; or the chilling effect of the Public Charge Rule, which now makes participating in the USDA Supplemental Nutrition Assistance Program, among other federal social assistance programs grounds for denying a lawful path to citizenship. ${ }^{15-17}$

\section{METHODS}

All 50 US states and the District of Columbia, 5 US territories (Puerto Rico, US Virgin Islands, Guam, the Commonwealth of Northern Mariana Islands, and American Samoa), and the US Department of Interior Bureau of Indian Education (BIE) comprise the study sample $(\mathrm{N}=57)$. Tribal-level assessments were not conducted for the BIE schools because the University of Arkansas Indigenous Food and Agriculture Initiative, a member of the Healthy Eating Research, a national program of the Robert Wood Johnson Foundation, and the Nutrition and Obesity Policy Research and Evaluation Network ad hoc joint COVID-19 School Nutrition Implications Working Group, was simultaneously developing a resource highlighting examples of meal service provision among BIE schools. ${ }^{18}$ Review by the Institutional Review Board was not required for this study because human subjects were not involved, as per the US Department of Health and Human Services guidelines. ${ }^{19}$ For all jurisdictions, web-based searches were conducted to identify emergency declarations, school closure announcements, and meal provision information during COVID-19related school closures between late February and May 2020. Data were extracted to identify key documents, their dates of publication, and administering agencies/departments.

\section{Scoring Categories}

Initial data extraction and coding were guided by research on best practices for summer meal provision and administrative agency policy to enhance nutrition programming. ${ }^{14,15,20,21}$ Two coders (GMM and SF) with experience in policy analysis conducted and compared their initial data extraction strategies and open coding notes to establish consensus and develop an initial set of coding domains. ${ }^{22,23}$ Following inductive analysis, websites were coded for all 57 jurisdictions before meeting with members of the multidisciplinary Healthy Eating Research Nutrition and Obesity Policy Research and Evaluation Network COVID-19 School Nutrition Implications Working Group ${ }^{24}$ to refine coding classifications, finalize the domains, and develop a scoring system to capture the comprehensiveness of information available for each domain.

On the basis of initial coding and working group input, 7 criteria were identified (Table 1) to account for the importance of crisis communication with internal-external stakeholders. ${ }^{25}$ These were (1) COVID-19 emergency declarations, which determine the legal and operational resources available to respond to an emergency, with implications for the government, private sector, and the public; (2) school closure announcements, which announced if and for how long schools would provide essential services during closures; (3) jurisdictions' COVID-19 dedicated websites regarding meal service for LEAs and families; (4) information regarding meal site locations and hours; (5) guidance on communication and outreach to families; (6) meal provision implementation guidance for LEAs; and (7) partnership with antihunger organizations, reflecting communication recommendations between these organizations, schools, and families during school closures. ${ }^{20}$ Using the information extracted from each jurisdiction, each criterion above received a grade of low (coded 0 ), moderate (coded 1 ), or high (coded 2) depending on the comprehensiveness of the information provided (Table 1 provides detailed scoring information).

\section{Deductive Coding and Appraisal}

Following development and standardization of the coding structure, the 2 coders scored jurisdictions during the week of March 23-30, 2020, to establish a baseline comprehensiveness score and during the weeks of April 6-20, 2020, to capture 
Table 1. Scoring Scheme to Assess the Comprehensiveness of 7 Criteria in Crisis Communication With Internal and External Stakeholders

\section{Score}

\section{Criterion}

1. Emergency declaration: mentions/ references school or meal provisions

\section{School closure} declaration: mentions/references meal provisions

3. Providing information on school meals on the main DOE/DOA COVID information/updates landing page

\section{School meal sites (locations/dates/h) \\ 5. Guidance on com- munication/out- reach to families}

\section{Emergency meal service implemen- tation guidance}

\section{Partnering with antihunger advo- cacy organization}

\begin{tabular}{ccc}
\hline $\mathbf{0}=$ Low & $\mathbf{1}=$ Moderate & $\mathbf{2}=$ High \\
$\begin{array}{c}\text { No specific mention } \\
\text { relating to schools }\end{array}$ & $\begin{array}{c}\text { General reference to other state } \\
\text { agencies, such as schools }\end{array}$ & $\begin{array}{c}\text { Specific school mention within } \\
\text { declaration }\end{array}$
\end{tabular}

No mention

No information on school meals on the main COVID-19 landing page

\section{None listed/difficult to find}

\section{No guidance on how to communicate with families specifically
Some verbiage about the importance of communicating with families about school meal provisions

Nothing more than waivers and USDA documentation listed
No mention of state partnering with anti- hunger organization or links to local organi- zations during school meal provisions

\section{General reference to essential services}

School meals are mentioned on the main landing page with very limited information for families and/or schools (eg, 1 or 2 links, out-of-date information, or only information for schools and not families)

Listed but not in an easily accessible form
Some documents listed such as Q\&A
Provides only links to state emergency food resources (ie, state food banks, United Way) but no mention of how they are partnered with school meal provisions

\section{School meals mentioned}
Detailed information on school meals for both schools and families provided on the main landing page (including links to waivers, best practices, school meal sites)

Shown in GIS map or other easily interpretable form and/or a number to text provided

A dedicated section for families with clear communication (eg, Q\&As, meal site maps)
Updated Q\&A document, best practices document/text, and other resources available and easy-to-find
Lists partnership with antihun- ger groups for school meal provision or mapping

COVID indicates coronavirus disease; COVID-19, coronavirus disease 2019; DOA, Department of Agriculture; DOE, Department of Education; GIS, geographic information system; Q\&A, Question and Answer.

changes in responses and reassign scores, when appropriate. Consensus coding was applied, whereby discrepancies between the 2 coders were discussed, and a final code was applied based on discussion and review of the data sources for each jurisdiction. Because of a delayed meal provision timeline in some US territories, in May 2020, a final round of data collection and coding was supplemented by a third coder with expertise in US territories' nutrition assistance programs. The initial 2 coders analyzed trends and sought feedback from the wider research team as a means of peer debriefing. ${ }^{26,27}$ Furthermore, all coders maintained an audit trail by taking consistent notes during each round of coding, and documenting code changes over time. ${ }^{27}$ Only scores from the final round of coding were retained in data analysis.

All data were organized in Microsoft Excel (Microsoft, Redmond, WA). Salient extracts from documents and examples were used to illustrate best practices and areas to be strengthened. Frequencies in each criterion were calculated, generating a percentage of the sample coded as 0 (low), 1 (moderate), or 2 (high) for each criterion at each time point.
Finally, Geographic Information System Software (ArcGIS, Esri, Redlands, CA) was used to visualize the variability in scoring criterion across states. Data were joined to a US state boundary shapefile, and colored symbology was generated based on quantitative values. $^{28}$

\section{RESULTS}

Below and in Figure 1, scores have been summarized for each criterion and examples of strategies used by jurisdictions, including examples of more and less comprehensive strategies (Table 2), have been provided. 


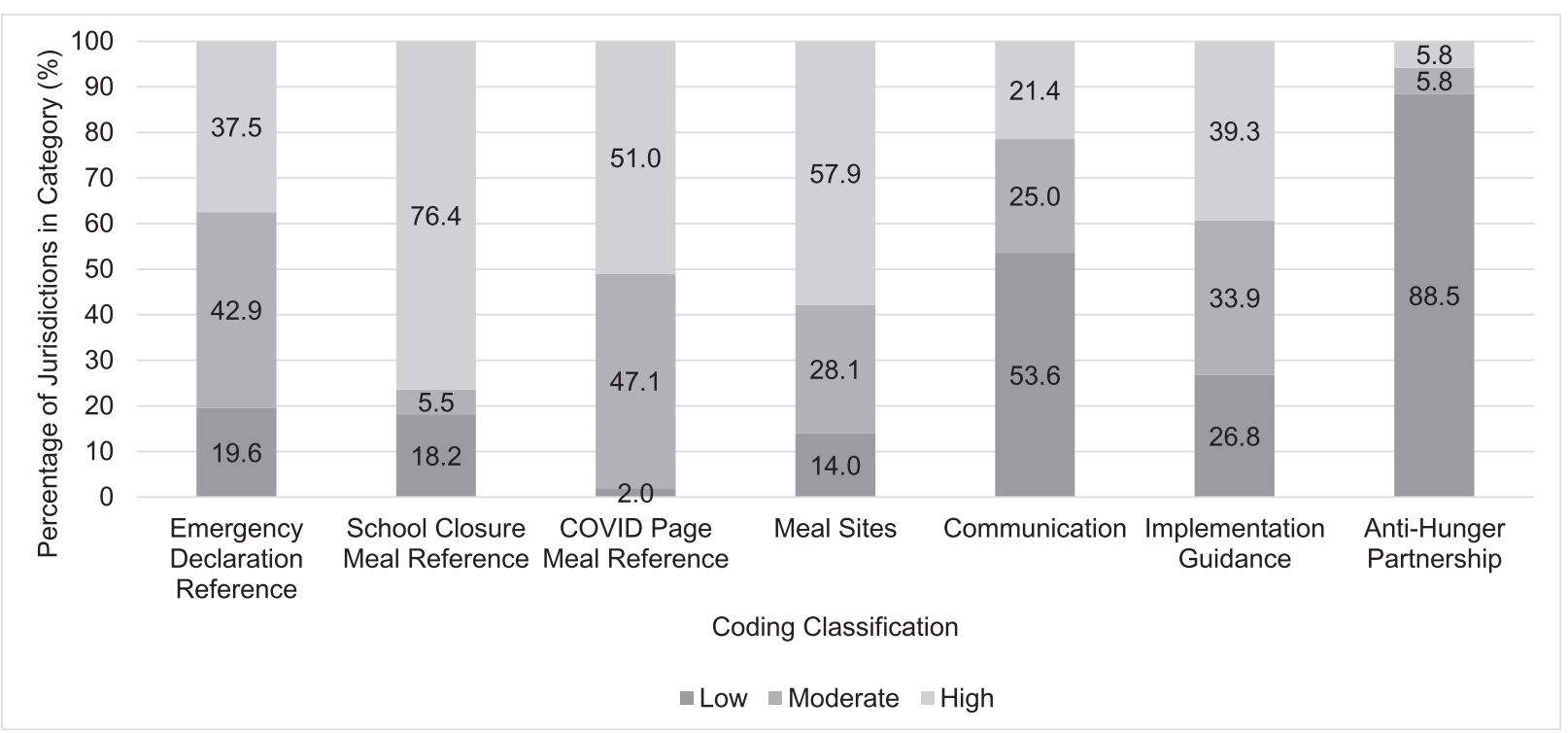

Figure 1. Nationwide trends in coronavirus disease 2019 nutrition response communication and outreach. COVID indicates COVID-19. Note: Sample sizes differ depending on usage of data. Emergency declaration reference of school closures ( $n=56$ states/territories); school closure meal reference $(n=53$ states/territories); education COVID page reference ( $n=51$ states/territories); meal sites $(n=56$ states/territories); communication/outreach $(n=56$ states/territories); implementation guidance ( $n=56$ states/territories); antihunger partnership ( $n=51$ states/territories).

Figure 2 provides a spatial overview of coding results, demonstrating regional trends in responses.

\section{Emergency Declarations $(\mathrm{n}=56$, Missing: BIE)}

Between January 29 and March 20, 2020, all jurisdictions declared a state of emergency in response to COVID19. Kindergarten through 12th-grade schools were specifically mentioned in just over one-third of declarations $(37.5 \%, \mathrm{n}=21)$. School-related content in the declarations varied greatly. For example, South Carolina's emergency declaration and American Samoa's amended declaration closed schools, and Maine recommended ending schools as reasonably as practical and consistent with their governor's authority. Several declarations discussed how the secretary of education had the authority to make decisions (eg, Alabama, Illinois, Pennsylvania), whereas others only discussed the importance of keeping schools operational and abreast of COVID-19 related developments (eg, Arkansas, Delaware, Minnesota, New Hampshire, New Jersey). The jurisdictions receiving the highest scores were those with the strongest and most specific language related to schools, including creating a task force or interagency working group to address school needs (eg, District of Columbia, Michigan) or directing the secretary of education to develop a contingency plan for school closing (eg, Vermont). None of the declarations mentioned school meal provisions; however, a small number discussed the importance of mobilizing resources, including food, to promote general welfare (eg, Alaska, Kentucky, New Mexico, US Virgin Islands).

\section{School Closure Announcements ( $\mathrm{n}=55$, Missing: Northern Marianas, Puerto Rico)}

All school closure announcements and extensions examined were announced by the Governor, Secretary of Education, and/or the State Board of Education. Schools were ordered closed state or territory-wide in all jurisdictions for the remaining 2019-2020 academic year except for the BIE, California, Florida, Kentucky, Idaho, Maine, Montana, South Dakota, Tennessee, and Wyoming, in which LEAs made closure and reopening decisions. The medium of the announcement varied: some jurisdictions had formal executive orders, whereas other announcements were made via press conference or press release. Jurisdictions differed in how quickly they acted to close schools following state of emergency declarations, ranging from the same day in 6 jurisdictions to 15 days in Hawaii. In some jurisdictions, some districts closed before the statewide decision. More than half of the jurisdictions gave their local school foodservice operators less than 72 hours notice between the announcement and when school closures were to begin $(61.1 \%, \mathrm{n}=33)$. The majority of closures discussed meal provision $(81.8 \%, \mathrm{n}=45)$; stronger examples recognized that children depend on the food they receive during the school day while also acknowledging the unique disease transmission risks that the school food service staff must mitigate to provide meals successfully (eg, Kansas, Maine). Others (eg, Arkansas, Pennsylvania, Kentucky) mentioned that they were requesting waivers from the USDA for greater flexibility in meal provision. 


\section{Coding Variable}

State declaration

school reference

School closure meal reference

Meal sites

unication/ outreach

Implementation guidance

\section{Antihunger partnership}

Education COVID page reference

\section{Strong/Comprehensive Examples}

"If an LEA closes..., provide school meals in noncongregate settings through the Summer Food Service Program and Seamless Summer Option, consistent with the requirements of the California Department of Education and US Department of Agriculture"

"All schools should work with their local governments and county health departments to determine appropriate meal provision, child care, or other community uses of school facilities or resources while complying with all directives regarding social distancing, hygiene, and other methods of slowing the spread of COVID-19."

Providing a Find a meal site near you search option within websites to enhance usage and access to nutrition resources.

Specific section of the website titled For parents with translation in to Spanish

Providing a separate Q\&A document for parents.

Updated Q\&A document with date stamps to show frequent updates

Provide adaptations to USDA waivers/guidance such as grab and go implementation to meet unique needs in the community.

A dedicated website (linked to on the main agency website) that highlights a partnership with a trusted state antihunger organization. The organization helped provide a meal site map, resource hotline available in multiple languages, information from advocacy organizations, and materials and guidance for outreach.

On the main COVID-19 landing page, a link to a child nutrition resources website, which contained separate sections with (1) information for families, (2) guidance for schools, (3) information about P-EBT, (4) a Q\&A document, and (5) links to recordings of recent town hall sessions.
Weaker/Less Comprehensive Examples

No specific mention of the state Department of Education.

No specific mention in the school closure executive order or other official close order communication.

PDF or downloadable Excel file with list of meal sites.

List displayed on website but no means of downloading files/interactive viewing.

Encouragement for schools/districts to use regular communication channels to convey meal service strategies and sites to parents/families.

Posting of waivers that allow parents to pick up meals on behalf of children.

Posting USDA Q\&A documents Providing guidance from Seamless Summer Option or Summer Food Service Program guidance and how to become a licensed meal site.

No partnership with antihunger organization or mention of any other antihunger local resources such as food banks or resource hotlines.

On the main COVID-19 landing page, no mention of school meals or any other child nutrition programs.

COVID indicates coronavirus disease; COVID-19, coronavirus disease 2019; LEA, local education authority; P-EBT, Pandemic Electronic Benefit Transfer; Q\&A, Question and Answer.

Jurisdiction's COVID-19

Website Regarding School Meal Service $(n=51$, Missing: Kansas and All Territories Except US Virgin Islands)

All states (except Kansas) developed a COVID-19 landing page, and all but 1 of these websites provided some information or links to information on school meals. Among the US territories, a COVID-19 landing page was found only for the US Virgin Islands; the COVID-19 landing page in the Department of Education contained information about school meals. Almost half of jurisdictions (47.1\%, $\mathrm{n}=24$ ) had some information on the main COVID-19 landing page targeting either schools or families. Information for schools included guidance discussed below in the implementation guidance section. Information for families included communication discussed below in the meal sites and communication to families' sections. The remaining jurisdictions (51.0\%, $\mathrm{n}=26)$ were considered highly comprehensive because they provided information for both schools and families, often through a dedicated child nutrition section on their COVID-19 landing page.

\section{Meal Sites $(\mathrm{n}=56$, Missing: American Samoa)}

Information on locations where students could obtain meals during school closures, such as at 
a) Emergency Declaration

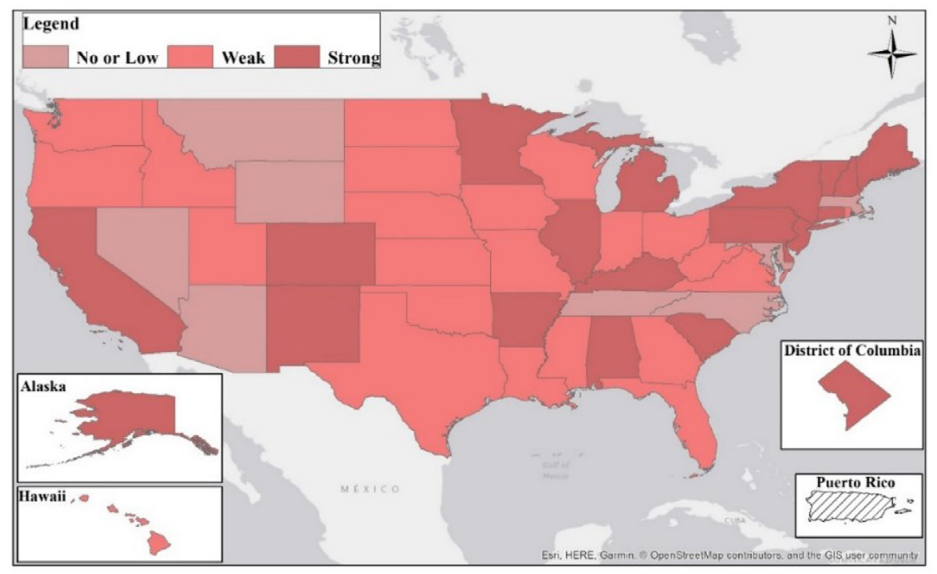

b) School Closure - Meal Provision

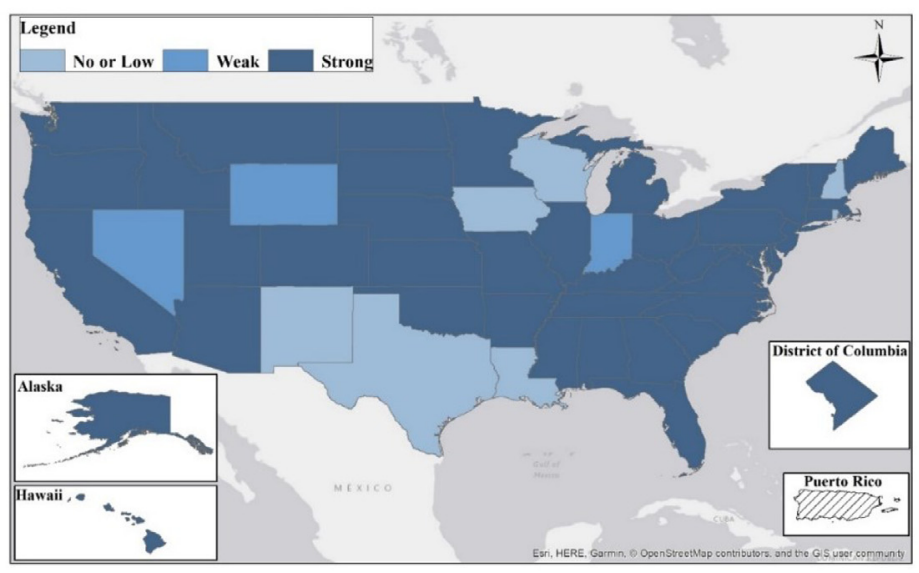

c) Education COVID Page Reference

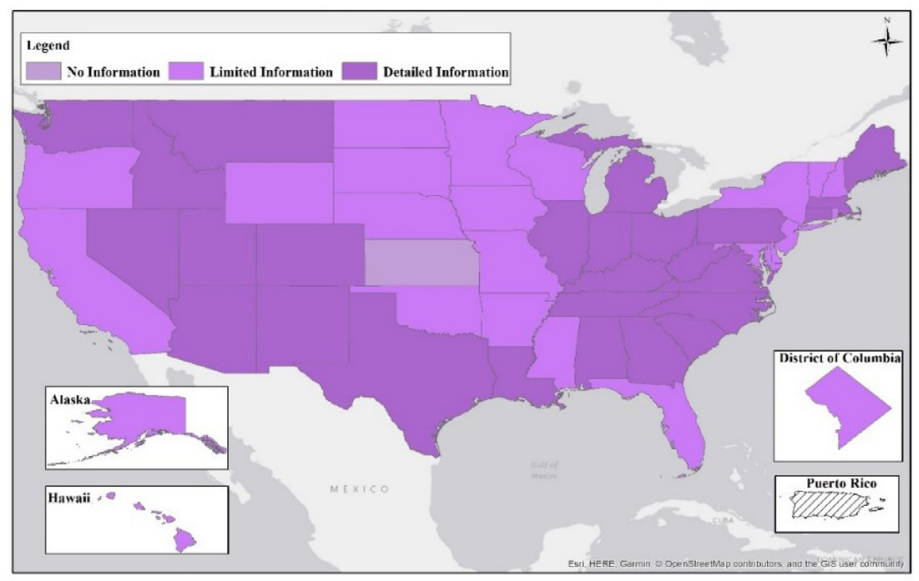

Figure 2. Results from geospatial analyses: (A) emergency declaration; (B) school closure-meal provision; (C) education COVID page reference; (D) meal site display and availability; (E) implementation guidance; (F) communication and outreach; $(G)$ partner with antihunger organization.

community sites or locations along bus routes, were provided on the websites of all but 8 jurisdictions. Of those with information, 16 provided moderately comprehensive information (ie, a score of $1,28.1 \%$ ), and 33
(57.9\%) highly comprehensive information. Jurisdictions that scored a 1 often provided lists of school meal sites in a downloadable format, which showed school meal site information (and often street address) or included a static list with no feature for finding the nearest location to the student. Those that scored a 2 had a find my meal site option on their website in which viewers could type in their zip code to find the nearest site, or a list of districts was displayed and the viewer could click on their district, revealing a list of meal sites with interactive links.

Outreach to Families $(\mathrm{n}=56$,
Missing: American Samoa)

Thirty jurisdictions (53.6\%) did not guide LEAs on how to communicate with families about school meal options or provide resources directed toward families to navigate meal service. One-quarter of jurisdictions ( $\mathrm{n}=14,25.0 \%)$ provided few resources, but some guidance, such as a Question and Answer (Q\&A) document instructing how schools communicate with families or provide a texting line on the find my meal site website with information on steps to minimize risk of COVID-19 transmission during meal provision. For the 12 jurisdictions (21.4\%) who were given a highly comprehensive rating, the website provided a specific section for families, which housed Q\&A guiding documents, or provided flyers regarding how to access school meals, which were often translated into multiple languages.

\section{Implementation Guidance ( $\mathrm{n}=56$, Missing: American} Samoa)

Many jurisdictions provided meal provision guidance to LEAs, including information on safety protocols and flexibilities granted through USDA. This information came in the form of $Q \& A$ documents, links to the USDA waiver documents, and/or implementation guidance documents. Jurisdictions that received the lowest scores $(26.8 \%, \mathrm{n}=15)$ only provided links to USDA waivers and 1 or 2 other resources, such as Q\&A 
d) Meal Site Display and Availability

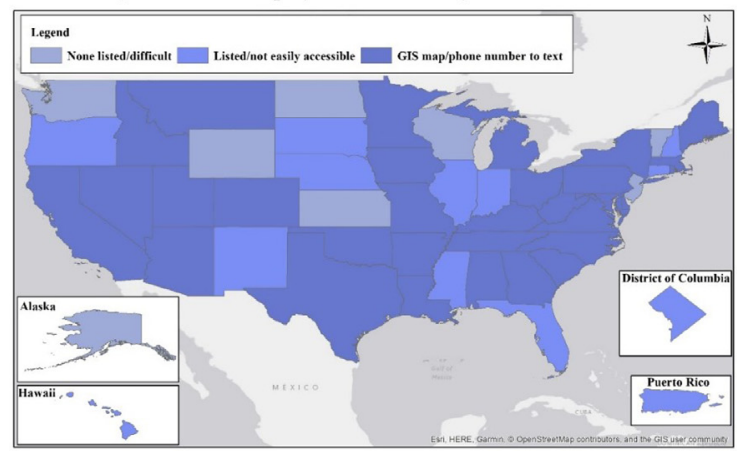

e) Implementation Guidance

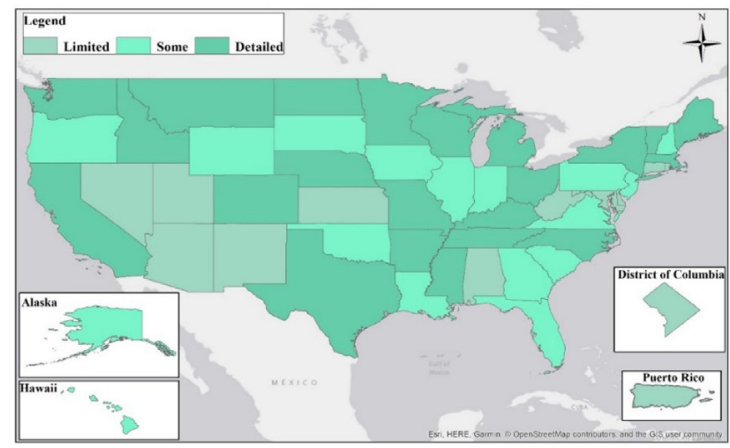

f) Communication and Outreach

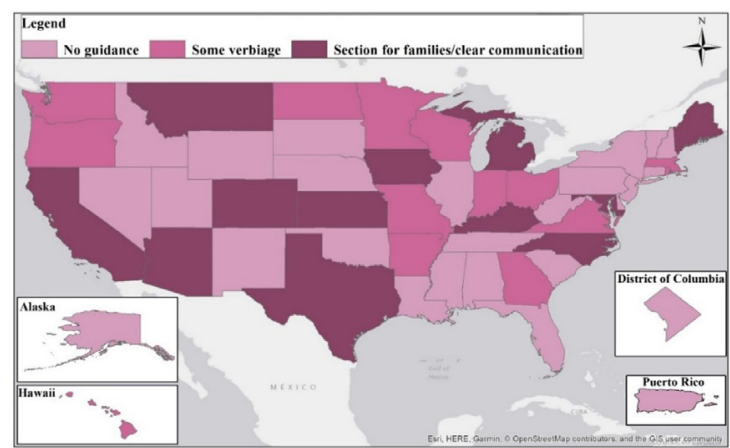

g) Partner with Antihunger Organization

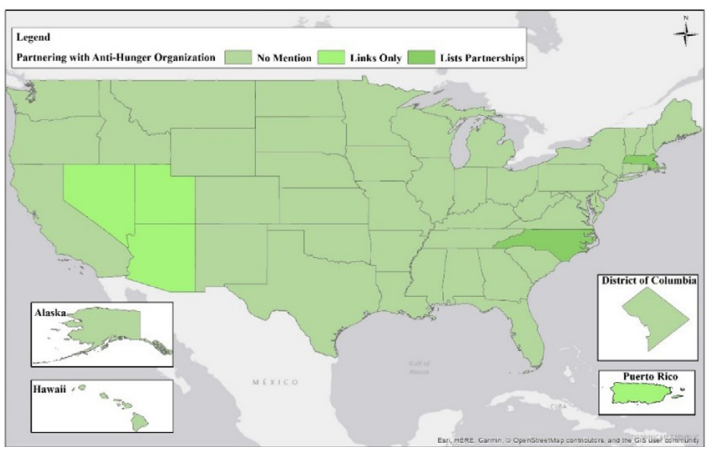

Figure 2 Continued.

documents created by the USDA. Jurisdictions with a moderately comprehensive score $(33.9 \%, \mathrm{n}=19)$ displayed USDA waiver information plus additional state-specific previous category, plus frequently updated their Q\&A documentation with date stamps (eg, updated on 4/ 24/2020), and provided more detailed guidance for food service staff through presentations, PDF documents, and other resources.

\section{Partnership With Antihunger Organizations ( $\mathrm{n}=52$, Missing: All US Territories Except Puerto Rico)}

Only 6 jurisdictions (11.6\%) provided information on their websites regarding collaboration with antihunger organizations (eg, Arizona, Massachusetts, Nevada, North Carolina, Puerto Rico, Utah) to provide meals or referral to antihunger organizations for additional food resources. In the 3 states rated as taking a moderately comprehensive approach, links to antihunger organizations, such as local food banks or a hotline with information on food resources, were provided on the administering agency's website. In the 3 states considered highly comprehensive, antihunger organizations worked directly with the jurisdiction to support meal service provision by providing mapping services to help users identify nearby meal sites.

\section{DISCUSSION}

This study aimed to conduct a novel nationwide assessment of child nutrition administrative agencies' responses and communications to internal and external stakeholders regarding meal service provision during the COVID-19 pandemic-related school closures. Understanding initial jurisdictions' approaches are critical to current and future emergency planning during school closures and reopening to help address food insecurity, limit disease transmission, and prevent health disparities, particularly among at-risk populations. ${ }^{29}$

Few jurisdictions referred to schools in emergency declarations, in which the majority of jurisdictions' pandemic response began. However, most jurisdictions discussed meal provision in school closure announcements, referencing the importance and necessity of meals or 
nutrition to priority populations. Even with recent experiences with natural disasters and resulting school closures, only 3 of the 5 US territories (Guam, US Virgin Islands, and the Commonwealth of Northern Mariana Islands) mentioned school meal service in their school closure announcements. The NSLP and SBP have been used in past natural disasters; for example, USDA foods (commodities) stored at schools have been used by the Emergency Food Assistance Program in food distribution, and school cafeterias/food supplies have been used in mass feedings. ${ }^{30}$ During natural disasters, schools in affected areas, can request that all students be eligible for free NSLP/SBP once schools are in session. ${ }^{31}$ Neither of these past provisions were discussed in any of the information examined for this study, nor were either solid or complete foundations for feeding children during a pandemic in which disease mitigation required novel responses during prolonged school closures.

More than half of the jurisdictions announced school closures within days of an emergency declaration and adapted quickly to provide meal service information to various stakeholders, mobilizing dedicated school food service staff, among others, to deliver meals while mitigating disease transmission. Indeed, jurisdictions examined responded relatively quickly to COVID-19 school closures in the form of meal site information. This result demonstrated a concerted effort to promote participation in meal provision to reduce food insecurity. ${ }^{20}$ Findings from a recent analysis of missed meals during the pandemic between school closure and implementation of emergency meal programming estimated that over 300 million meals were missed/not served to eligible students in the first few weeks. ${ }^{11}$ Decreased meal counts compared with typical service were already documented in 4 of the nation's largest urban school districts, ${ }^{32}$ highlighting implications for placement and quantity of school/community meal sites and efforts to promote participation in supplementation nutrition programming. Accordingly, the ability for jurisdictions to act quickly was of high importance, given the potentially damaging effects of delays on food insecurity.

The study findings also highlight areas for improvement, particularly regarding the provision of highquality guidance to LEAs on how best to meet the needs of their community. For example, implementation guidance, while available in most jurisdictions, needed significant improvement. Because of the diverging contexts and populations served at meal sites across the country, jurisdictions that provided only generic USDA guidance missed an opportunity to provide tailored information to foodservice directors. Lack of guidance for foodservice staff has been found in prior research related to summer meal programs, ${ }^{14}$ and may hinder participation. Further research is needed to understand better foodservice directors and staffs' needs and gaps in professional development, technical assistance, and capacity building in advance of meal service disruptions. $^{2,33}$ Given the spatial variability in the implementation of practices, future research could examine the role of national-level guidance to decrease the risk of significant state and local variation with the most likely to exaggerate health disparities.

Similarly, easy-to-find and updated information about school meal provisions directed at families could be significantly improved, given that 30 jurisdictions $(53.6 \%)$ did not provide any guidance for LEAs. Even the most comprehensive examples only provided information in their Q\&A document or minimalist template communication for schools/districts to disseminate. Although this study did not capture real-time communication (ie, training sessions, live Q\&A, etc), if these did occur, a best practice would be to list these on publicly available web-based information or upload the recordings of such training so that others could learn from guidance on outreach and provide a clear, unified message to families. Estimates suggest that about half of users never make it past the main landing page for a website. ${ }^{34}$ During future unplanned school closures, jurisdictional leadership, child nutrition administrative agency staff, and website designers should collaborate to ensure that information about meal provision is prioritized and presented clearly and accessibly on a live dashboard.

Most of the messaging around meal service provision during this pandemic was to help avoid student hunger and did not address concerns about obesity prevention, even when explaining how LEAs could provide multiple meals at one time. A recent commentary explained how this pandemic would likely exacerbate risk factors for weight gain associated with summer breaks, given students will likely snack more frequently, exercise less, engage in more sedentary behaviors such as e-learning, and face unprecedented social and emotional stress. ${ }^{35-37}$ Nonetheless, addressing food insecurity within school communities is a concrete step to increasing the overall health of children and families, and promoting consumption of nutritious foods and beverages is an important feature in such programming with less emphasis on preventing obesity because of the complex and dynamic factors impacting obesity prevalence. Accordingly, more work is needed to ensure clarity in these dual public health messages to mitigate food insecurity and, ultimately, chronic disease risk. ${ }^{38,39}$ Future emergency planning could better mobilize the role of Supplemental Nutrition Assistance Program Education and extension in developing and disseminating these key food, nutrition, and health messages, particularly for vulnerable populations. ${ }^{40}$

Another area for future research is to examine if interactive maps and mobile/text interaction systems to find meal sites led to greater adoption and use of emergency school meal programs; currently, some guidance supports their use as best practice for helping bolster participation in summer meal programs. ${ }^{14,20,41}$ Moreover, given the limited reach of school meal sites in some regions, partnerships with and referrals to trusted antihunger community organizations can extend the reach of emergency food services. ${ }^{20}$ Few cases of these partnerships were observed. For example, Share Our Strength, a national antihunger organization, recommends administrative agencies 
work with local sponsors to promote meal site locations and hours through online platforms in multiple languages and engage key stakeholders such as families and faith-based organizations to enhance program implementation and reach. In preparation for future unplanned closures because of emergencies, LEAs should develop and keep up-to-date lists of local antihunger organizations that can be posted on their websites. Antihunger organizations should be involved in state and local emergency planning, and details about how these organizations can serve as potential partners for meal service provision during emergencies should be formally incorporated into planning.

These analyses are limited to webbased information and do not include systematic evaluation of communications sent by e-mail, social media, phone, or text between the child nutrition program administrative agencies and LEAs or communities. This study did not include jurisdictional responses or communications regarding Pandemic Electronic Benefits Transfer, which was initiated in most states after the study period. ${ }^{42}$

\section{IMPLICATIONS FOR RESEARCH AND PRACTICE}

Individually and collectively, emergency declarations, school closure announcements, COVID-19related websites, and child nutrition administrative agencies' websites were and will continue to be important communication channels for ensuring that children maintain access to meals during school closures and reopening. ${ }^{2,34}$ Although it is not surprising that none of the jurisdictions examined executed a comprehensive plan to address food insecurity during a pandemic of this nature and school closures of this duration, the initial responses to COVID-19 should serve as important foundations for lessons learned as this pandemic persists and as jurisdictions work to better plan for future emergencies. Translating this evidence into action is important, given the rising prevalence of food insecurity across the nation.
Indeed, 1 study found that by the end of April 2020, more than 1 in 5 households in the US, and 2 in 5 households with mothers with children $\leq 12$ years were food insecure. ${ }^{11,43}$

Model language for emergency declarations and school closure announcements, along with other relevant actions that recognize the important role schools play in ensuring daily access to nutritious, safe meals for children participating in the school-based federal nutrition programs, would greatly enhance the timeliness and quality of action from jurisdictions. Furthermore, guidance on establishing communication pathways between schools, districts, and jurisdictions would be instrumental in rapid decision making and use of data to drive such decisions at each level of implementation.

Findings showed spatial variability in meal service strategies, with suggestions of regional homogeneity and instances of jurisdiction divergence. Further research could aim to understand the reach and adoption among varying COVID-19 meal service strategies within and between jurisdictions. ${ }^{11}$ Given Congress' authorization of USDA waivers to allow for the use of noncongregate meal service, future research is warranted to understand if jurisdictions with higher participation in, and a long history of, summer meal programs were able to initiate programs and meal site web-based finders faster and more comprehensively. Furthermore, facilitated by the meal counting/tracking systems already in place to track participation, jurisdictions may wish to pilot specific meal service strategies (ie, a week's worth of food, food delivery on bus routes) in areas of high food insecurity and examine the rates of participation; as a result, providing localized data which could drive policy and practice decisions.

Finally, a key theme for future practice is the use of local stakeholders in implementing emergency school meal programming. Findings demonstrated that (1) partnerships with antihunger organizations/ other centers were minimal or poorly communicated, and (2) communication and outreach efforts to families and communities were scant. These 2 areas of concern present innovation opportunities, particularly in developing partnerships and optimizing available resources from local organizations. Ongoing research and practice should examine more extensively local-level meal service responses during emergencies, including the role of local Parent Teacher Associations, media, health departments, advocacy, and social service support organizations, school leadership, and school food service staff through case studies and cross-jurisdiction comparisons. Guidance from the USDA and Share Our Strength No Kid Hungry, ${ }^{44}$ among others, could potentially serve as a key reference point for jurisdictions to enhance consistency across the nation in response to school closures.

\section{ACKNOWLEDGMENTS}

All authors are members of the Healthy Eating Research Nutrition and Obesity Policy Research and Evaluation Network COVID-19 School Nutrition Implications Working Group. Healthy Eating Research is a national program of the Robert Wood Johnson Foundation. Nutrition and Obesity Policy Research and Evaluation Network is supported by CDC's Division of Nutrition, Physical Activity, and Obesity Cooperative Agreement no. 5U48DP00498-05. Healthy Eating Research provided stipend support to Sheila Fleischhacker as co-chair of the Working Group and Nutrition and Obesity Policy Research and Evaluation Network provided fellowship support to Gabriella M. McLoughlin and Caroline G. Dunn.

The authors are grateful to both Healthy Eating Research, a national program of the Robert Wood Johnson Foundation, and the US Department of Health and Human Services CDC Division of Nutrition, Physical Activity, and Obesity-supported Nutrition and Obesity Policy Research and Evaluation Network for their support of an ad hoc joint COVID-19 School Nutrition Implications Working Group. 


\section{REFERENCES}

1. Education Week. Map: coronavirus and school closures in 2019-2020. https:// www.edweek.org/ew/section/multimedia/map-coronavirus-and-schoolclosures.html. Accessed May 2, 2020.

2. Dunn CG, Kenney E, Fleischhacker SE, Bleich SN. Feeding low-income children during the Covid-19 pandemic. N Engl J Med. 2020;382:e40.

3. Fleischhacker SE, Moran A, Bleich SN. Legislative and executive branch developments affecting the United States Department of Agriculture Supplemental Nutrition Assistance Program. J Food Law Policy. 2019;15:131-247.

4. Ollinger M, Guthrie JF, Peo A. USDA school meal programs: how and why the cost of food purchases varies across locales. Washington, DC: US Department of Agriculture; 2018. https:// www.ers.usda.gov/webdocs/publications $/ 90600 /$ err-260.pdf? $\mathrm{v}=5933.8$. Accessed May 20, 2020.

5. Gordon A, Oddo V. Addressing Child Hunger and Obesity in Indian Country: Report to Congress. Washington, DC: Mathematica Policy Research; 2012. https://fns-prod.azureedge.net/sites/ default/files/IndianCountry.pdf. Accessed May 20, 2020.

6. Hipp JS, Duren CD. Regaining Our Future: An Assessment of Risks and Opportunities for Native Communities in the 2018 Farm Bill. Prior Lake, MN: Shakopee Mdewakanton Sioux Community; 2017. https://jm4.e6c.myftpupload.com/wp-content/uploads/ 2019/12/Farm-Bill-Report_WEB.pdf. Accessed May 20, 2020.

7. US Department of Agriculture. State guidance on coronavirus pandemic EBT (P-EBT). https://www.fns.usda.gov/ snap/state-guidance-coronavirus-pandemic-ebt-pebt. Accessed May 2, 2020.

8. US Department of Agriculture. FNS response to COVID-19: child nutrition programs. https://www.fns.usda.gov/ disaster/pandemic/covid-19. Accessed May 2, 2020.

9. US Department of Agriculture. Nutrition Program Fact Sheet: Schools/Child Nutrition USDA Foods Programs. Washington, DC: US Department of Agriculture; 2018. https://fns-prod.azureedge.net/sites/ default/files/resource-files/USDAfisfactsheet.pdf. Accessed May 12, 2020.

10. Congressional Research Service. School Meals Programs and Other USDA Child Nutrition Programs: A Primer.
Washington, DC: Congressional Research Service; 2019. https://fas. org/sgp/crs/misc/R43783.pdf. Accessed May 12, 2020.

11. Kinsey EW, Hecht AA, Dunn CG, et al. School closures during COVID19: opportunities for innovation in meal service. Am J Public Health. 2020;110:1635-1643.

12. Turner L, Leider J, Piekarz-Porter E, et al. State laws are associated with school lunch duration and promotion practices. J Acad Nutr Diet. 2018; 118:455-463.

13. Story M, Nanney MS, Schwartz MB. Schools and obesity prevention: creating school environments and policies to promote healthy eating and physical activity. Milbank Q. 2009;87: 71-100.

14. Cullen D, Blauch A, Mirth M, Fein J. Complete eats: summer meals offered by the Emergency Department for Food Insecurity. Pediatrics. 2019;144:e20190201.

15. Turner L, O'Reilly N, Ralston K, Guthrie JF. Identifying gaps in the food security safety net: the characteristics and availability of summer nutrition programmes in California, USA. Public Health Nutr. 2019;22:1824-1838.

16. Bernstein H, McTarnaghan S, Gonzalez D. Safety Net Access in the Context of the Public Charge Rule. Washington, DC: Urban Institute; 2019. https:// www.urban.org/sites/default/files/ publication/100754/safety_net_access_in_the_context_of_the_public_charge_rule_2.pdf. Accessed May 20, 2020.

17. Bleich SN, Fleischhacker S. Hunger or deportation: implications of the Trump Administration's proposed public charge rule. J Nutr Educ Behav. 2019; 51:505-509.

18. University of Arkansas, Indigenous Food and Agriculture Initiative. Meal Service in Indian Country. Fayetteville, AR: University of Arkansas; 2020. https://jm4.e6c.myftpupload.com/wpcontent/uploads/2020/03/SchoolFood-Service-Resources-3.20-1.pdf. Accessed March 25, 2020.

19. US Department of Health and Human Services. Human subject regulations decision charts. https://www.hhs.gov/ ohrp/regulations-and-policy/decisioncharts/index.html\#c1. Accessed March 20, 2020 .

20. No Kid Hungry. Summer meals. http://bestpractices.nokidhungry.org/ programs/summer-meals. Accessed December 5, 2020.
21. Centers for Disease Control and Prevention (DHHS/PHS). Results from the School Health Policies and Practices Study. Atlanta, GA: Centers for Disease Control and Prevention; 2016. https:// www.cdc.gov/healthyyouth/data/ shpps/pdf/shpps-results_2016.pdf. Accessed June 12, 2020.

22. Glaser BG, Strauss AL. The Discovery of Grounded Theory: Strategies for Qualitative Research. Chicago, IL: Aldine; 1967.

23. Strauss A, Corbin J. Basics of Qualitative Research: Techniques and Procedures for Developing Grounded Theory. 4th ed. Thousand Oaks, CA: Sage Publications; 2015.

24. Nutrition and Obesity Policy Research and Evaluation Network. COVID-19 response. https://nopren.org/covid19/. Accessed November 5, 2020.

25. Centers for Disease Control and Prevention. Program Performance and Evaluation Office (PPEO). Introduction to program evaluation for public health programs: a self-study guide. https://www. cdc.gov/eval/guide/step1/index.htm.

Accessed May 20, 2020.

26. Whittemore R, Chase SK, Mandle CL. Validity in qualitative research. Qual Health Res. 2001;11:522-537.

27. Lincoln YS, Guba EG. Naturalistic Inquiry. Beverly Hills, CA: Sage Publications; 1985.

28. Cromley EK, McLafferty SL. GIS and Public Health. 2nd ed. New York, NY: The Guilford Press; 2011.

29. Abrams EM, Szefler SJ. COVID-19 and the impact of social determinants of health. Lancet Respir Med. 2020;8:659-661.

30. US Department of Agriculture. The Emergency Food Assistance Program. https://www.fns.usda.gov/tefap/emergency-food-assistance-program. Accessed September 23, 2020.

31. US Department of Agriculture. FNS disaster assistance. https://www.fns. usda.gov/disaster/disaster-assistance. Accessed September 23, 2020.

32. McLoughlin GM, McCarthy JA, McGuirt JT, Singleton CR, Dunn CG, Gadhoke P. Addressing food insecurity through a health equity lens: a case study of large urban school districts during the COVID-19 pandemic [published online ahead of print September 21, 2020]. J Urban Health. https://dx.doi.org/10.1007\%2Fs11524020-00476-0.

33. Fleischhacker S, Campbell E. Ensuring equitable access to school meals. J Acad Nutr Diet. 2020;120:893-897. 
34. Rocket Fuel. What's the average bounce rate for a website? https://www. gorocketfuel.com/the-rocket-blog/ whats-the-average-bounce-rate-in-google-analytics/. Accessed May 27, 2020.

35. Rundle AG, Park Y, Herbstman JB, Kinsey EW, Wang YC. COVID-19related school closings and risk of weight gain among children. Obesity (Silver Spring). 2020;28:1008-1009.

36. Wang YC, Vine S, Hsiao A, Rundle A, Goldsmith J. Weight-related behaviors when children are in school versus on summer breaks: does income matter. $J$ Sch Health. 2015;85:458-466.

37. von Hippel PT, Workman J. From kindergarten through second grade, U.S. children's obesity prevalence grows only during summer vacations. Obesity (Silver Spring). 2016;24:2296-2300.

38. Kaur J, Lamb MM, Ogden CL. The association between food insecurity and obesity in children-The National

Health and Nutrition Examination

Survey. J Acad Nutr Diet. 2015; 115:751-758.

39. Seligman HK, Bindman AB, Vittinghoff E, Kanaya AM, Kushel MB. Food insecurity is associated with diabetes mellitus: results from the National Health Examination and Nutrition Examination Survey (NHANES) 1999-2002. J Gen Intern Med. 2007; 22:1018-1023.

40. US Department of Agriculture. SNAP - denial of certain requests to adjust SNAP regulations. https://www.fns. usda.gov/snap/covid-19/denial-certain-state-requests. Accessed September 23, 2020.

41. Ralston K, Treen K, Coleman-Jensen A, Guthrie J. Children's food security and USDA child nutrition programs. https://www.ers.usda.gov/ publications/pub-details/?pubid= 84002. Accessed May 20, 2020.

42. Center on Budget and Policy Priorities. CBPP/FRAC P-EBT documentation project shows how states implemented a new program to provide food benefits to up to 30 million low-income school children. https:// www.cbpp.org/pebt. Accessed September 23, 2020.

43. Bauer L. The COVID-19 crisis has already left too many children hungry in America. March 6, 2020. Washington, DC: The Brookings Institution; 2020. https://www.brookings.edu/ blog/up-front/2020/05/06/the-covid19-crisis-has-already-left-too-manychildren-hungry-in-america/. Accessed September 23, 2020.

44. No Kid Hungry. End child hunger in America. https://www.nokidhungry.org/. Accessed April 1, 2020. 